\title{
Representação da violência doméstica em produções seriadas brasileiras
}

\section{Representation of domestic violence in Brazilian serialized productions}

Monica Martinez ${ }^{1}$ e Samantha Nogueira Joyce ${ }^{2}$ do Programa de Pós-Graduação em Comunicação e Cultura da Universidade de Sorocaba (Uniso) e colíder da Rede de Pesquisa Narrativas Midiáticas Contemporâneas (Renami), ligada à Associação Brasileira de Pesquisadores em Jornalismo (SBPJor). Email: martinez.monica@uol.com.br. 


\section{Resumo}

A proposta deste artigo é refletir a respeito da representação da violência doméstica em relação a mulheres em narrativas seriadas televisivas. Trata-se de uma análise comparativa, com uma perspectiva crítica/ compreensiva, no campo dos estudos das narrativas e do imaginário. Este trabalho tem como corpus a telenovela Mulheres Apaixonadas (Globo) e o seriado Sessão de Terapia (Globosat News Television GNT). O intuito é analisar e contrastar como essas duas produções narrativas representam e apresentam a violência doméstica às suas respectivas audiências, levando-se em conta aspectos sobre produção, público, TV aberta e paga.

Palavras-chave

Narrativas midiáticas, séries, telenovelas, merchandising social, relações de gênero.

\section{Abstract}

The purpose of this article is to analyze the representation of domestic violence geared towards women in Brazilian serialized television narratives. It is a comparative analysis, with a critical/comprehensive perspective, borrowing from the narrative and imagined traditions. This work is a case study of the telenovela Mulheres Apaixonadas (Women in Love, Globo) and the series Sessão de Terapia (Therapy Session, Globosat News Television - GNT). Our purpose is to find out how these two narrative productions represent and present domestic violence to their respective audiences, taking into account aspects about production, public, open and paid TV.

\section{Keywords}

Mediated narratives, series, telenovelas, social merchandising, gender. 
Há uma linha tênue entre ficção e não ficção que pode ser encontrada espelhada nas representações das narrativas em geral e, por extensão, nas narrativas audiovisuais. As próprias palavras "ficção" e "realidade" são porosas, tão permeáveis a interpretações que têm sido usadas de forma muito cuidadosa por estudiosos do campo da comunicação e da informação. Nos estudos de jornalismo, por exemplo, a palavra realidade tem sido cada vez mais deixada para debate em outras áreas, como a filosofia, sendo substituída, de forma progressiva, por acontecimento (MOTTA, 2013; SODRÉ, 2009). E o que seria, ou melhor, não seria um acontecimento ficcional? Em jornalismo, por exemplo, está estabelecido desde pelo menos os anos 1980 que a construção de perfis feita por meio da técnica da composição de personagens reais - como a de Hugh Griffin Flood feita pelo jornalista estadunidense Joseph Mitchell (1908-1996) -, publicados na revista The New Yorker nos anos 1940, é entendida como literatura e não como uma prática aceita dentro dos cânones jornalísticos.

Aliás, a ênfase na separação entre personagens considerados reais e personagens tidos como imaginários é mandatória nesse campo da práxis e do saber, uma vez que a segunda é tratada como fraude devido a casos como o de Janet Cooke em 1980, no The Washington Post, e o de Jason Blair, no The New York Times, em 2003, além da de Sabrina Rubin Erderly, em 2014, na revista Rolling Stones. A edição de novembro de 2014 da publicação dos Estados Unidos continha "A rape on campus", escrita por Sabrina Rubin Erderly, reportagem que investigava um suposto estupro coletivo ocorrido na University of Virginia. Quando os dados da matéria foram questionados por veículos, como Slate e The Washington Post, Will Dana, editor da publicação por dezenove anos, assumiu responsabilidade pela falta de checagem das entrevistas, publicou um relatório da apuração no site da revista e pediu demissão. A repórter havia, como se diz em jargão jornalístico brasileiro, tomado uma "barriga", isto é, aceito como verdade as informações colhidas com a perfilada, "Jackie", que por sua vez havia inventado um salva-vidas fictício que teria liderado o estupro coletivo cometido contra ela (MARTINEZ; CORREIA; PASSOS, 2015). 
A noção de "verdade" almejada na prática jornalística, ressalta-se, é pertinente. Contudo, outros campos do conhecimento - que não teriam a premissa social de sentinela dos poderes públicos e privados como o jornalismo - entendem a questão de forma diferenciada. É o caso da história oral, que incorpora termos como "ucronia", idealizada em 1973 pelo historiador italiano Alessandro Portelli com o sentido de utopia, isto é, de resiliência à uma dada injustiça ou realidade existente (ALBERTI, 2005; MARTINEZ, 2016; MEIHY, 1998). Não por acaso, essa abertura a diferentes visões de mundo é base de métodos como a história de vida, uma vez que estes são baseados em relatos lastreados em grande parte na memória (BERTAUX, 2010; MARTINEZ, 2015; MARTINEZ; SILVA, 2017), como os entrevistados do cineasta brasileiro Eduardo Coutinho (1933-2014) (LINS, 2004).

O trânsito de narrativas ficcionais também impacta na produção jornalística. O motivo é que, em alguma medida, as produções audiovisuais podem exercer o papel de "agenda-setting", isto é, de se transformarem em fontes de notícias, não apenas no nível dos acontecimentos ligados aos seus protagonistas, mas também pelas reflexões sociais que desencadeiam sobre temas atuais por meio de práticas como a de marketing social (JOYCE; MARTINEZ, 2016). O ponto destacado neste artigo, portanto, se dá pela relação tradicional e complexa da mediação entre informação e entretenimento (SOARES; VICENTE, 2016), estando ligada ao avanço tecnológico sem precedentes (CASTELLS, 2005; JENKINS, 2009; MASIP et al., 2015), à natureza da cultura brasileira (CASTRO, 2015), com seus processos de antropofagia (SILVA, 2007) e hibridação (CANCLINI, 2000; MARTÍN-BARBERO, 2003; MARTÍN-BARBERO; REY, 2001), bem como à própria característica poética que tradicionalmente permeia as narrativas midiáticas (DRAVET, 2014).

\section{Sobre imaginários: construções imaginativas, porém com densidade do real}

É difícil falar de imaginário - ou melhor, talvez imaginários - sem falar de imagem, e vice-versa. Na origem da história da cultura, ambos se encontram imbricados, uma vez que provavelmente as origens da cultura humana remontam às imagens de um ser querido que, em sua efêmera vida até então - quiçá 30 
anos - não mais despertava do sono profundo. A morte, desde cerca de uns 80 mil anos (DE MASI, 2005), passa a ser o contraponto da vida e a pedra de toque da cultura humana (MARTINEZ, 2014; MORIN, 1997). Assim, a morte passa a ser uma canção sussurrada, o tema exclusivo e universal que dá sentido à vida (FLUSSER, 2002), ligando-se os acontecimentos à eminência ou ao medo de um fim anunciado, dos relatos de crises econômicas às catástrofes naturais ou humanas - como os ataques terroristas -, tendo, portanto, relação direta ou indireta com a violência e a morte. Nesse sentido, "a maioria das notícias seria mortal, causando simultaneamente medo e rejeição, atração e curiosidade" (BAITELLO JÚNIOR, 1997, p. 109).

A própria imagem - do latim, imago -, nasce como uma representação de uma ausência, sendo, desde sempre, um simulacro do real, uma vez que finge ser o que não é e não raro representa o que nunca existiu (BAUDRILLARD, 1991). Nesse contexto, vários autores sugerem que vivemos numa cultura do excesso das visualidades que, diferentemente de densas e criativas tradições brasileiras, como a antropofagia, estariam a nos esvaziar, pois que nos devorariam dos nossos sentidos norteadores da vida (BAITELLO JÚNIOR, 2014).

Como bem lembram Gomes e Soares (2015), uma imagem é, ao mesmo tempo, material e mental. É difícil segmentar a visão da contraparte material da mental, pois quais imagens seriam induzidas por estímulos materiais e quais, imaginadas, encontrariam sua materialidade no mundo? De toda forma, no âmbito dos estudos dos imaginários, interessa destacar dois pontos. O primeiro é o da recepção, referindo-se à fotografia a partir da perspectiva fenomenológica de Merleau-Ponty, Portanova Barros sugere que tudo o que possa ser objeto do olhar só chega a ser visto porque algo em nós o acolhe (2017, p. 161). O segundo, por sua vez, é a potência das imagens internas, chamadas endógenas (BELTING, 2007) - menos estudadas no campo da comunicação - , uma vez que seriam projetadas (JUNG, 2012) externamente na miríade de representações possíveis, incluindo as midiáticas - mas sempre lembrando que há um processo contínuo de retroalimentação. 
Finalmente, em uma tentativa de ir além da crítica das representações midiáticas (DEBORD, 1997), por mais necessária que ela seja, busca-se aqui uma abordagem integrativa e, portanto, compreensiva da realidade ( $\mathrm{KÜNSCH}$, 2014; MEDINA, 2014). Essa premissa alinha-se, teoricamente, à complexidade da contemporaneidade, bem como à noção de que, desde que as imagens rupestres eram pintadas nos recônditos das cavernas, o espetáculo sempre esteve associado intrinsecamente aos acontecimentos, visto que é entendido como ritual, isto é, uma reencenação de um mito. Este se insere, evidentemente, no contexto dos sistemas mitológicos poéticos (CAMPBELL, 2015, p. 137). Noção endossada por Cassirer, quando este afirma que o mito combina um elemento teórico e outro de criação artística, estando, portanto, associado à poesia (1994, p. 126). Já a maior parte das narrativas midiáticas perdeu esse caráter mitopoético, reduzindo-se à uma visão superficial e fragmentada da realidade (CONTRERA, 2010).

\section{Televisão e representação: telenovelas e séries}

Já sabemos que na América Latina as novelas desempenham um importante papel cultural nas experiências cotidianas das pessoas. Sabemos também que as novelas são altamente lucrativas, mas que além de serem um produto capitalista elas também são um espaço complexo de mediações/representações. Parte fundamental de sua característica é que essas narrativas melodramáticas de cerca de uma hora são transmitidas diariamente (de segunda a sábado) e que duram em média de seis meses a um ano. Mesmo com todas as inovações tecnológicas recentes, as novelas se apresentam como elemento básico da programação de TV no Brasil, em diversos horários da grade de programação, há mais de seis décadas (HAMBURGER, 2005; PASTINA, 2004; PORTO, 2012).

Ana Maria Balogh (2002, p. 96) lembra que as séries e os seriados foram primeiramente idealizados nos Estados Unidos, não por acaso a pátria do fordismo. Embora usados atualmente como sinônimos, em relação ao seriado, a série contém a noção de continuidade entre episódios, fundamental para a compreensão do conjunto. Já o seriado teria relação com o conto literário, com 
estrutura de começo, meio e fim, possibilitando certa unidade narrativa em cada episódio.

A história da televisão brasileira conta com séries famosas, como Malu Mulher que, criada e dirigida por Daniel Filho, foi exibida pela Rede Globo de 24 de maio de 1979 a 22 de dezembro de 1980. Nesse âmbito, Ramos (2016, p. 84) identifica em 33 anos, de Malu (1979) a Suburbia (2012), 28 seriados brasileiros que versam sobre a questão do feminino. Mais densas do ponto de vista dramatúrgico, as minisséries são entendidas como um produto de alta qualidade no cenário ficcional brasileiro. Tradicionalmente exibidas após as $22 \mathrm{~h}$, costumam ter mais de 30 capítulos e ser veiculadas durante os dias úteis, por uma ou mais semanas consecutivas (BALOGH, 2002, p. 96).

Cabe ressaltar que, no que diz respeito às novelas, de modo geral, as inserções de narrativas sobre a violência doméstica têm caráter de merchandising social, ou seja, narrativas educativas pró-sociais inseridas em diferentes núcleos da novela. Os temas podem variar desde planejamento familiar e doação de órgãos até o racismo e o tráfico de mulheres. Tradicionalmente, a inclusão dessas narrativas socialmente relevantes e de caráter educacional eram resultado da preferência e agenda político-social do autor(a). Contudo, a partir da década de 1990, a rede Globo começou a articular ativamente estratégias para que essas inserções fossem otimizadas com as ideias originais dos autores, permitindo maior impacto social (JOYCE, 2012; LA PASTINA; PATHEL; SCHIAVO, 2003).

Ainda que no Brasil as novelas venham persistindo nas grades de programação, a popularização dos canais por assinatura nos últimos anos, bem como a oferta de provedores de filmes e séries de televisão via streaming, como a Netflix, propiciaram uma avalanche de novos formatos televisivos (como as séries), muitos deles inspirados no universo dos profissionais de saúde, como psicólogos, psicoterapeutas, psicanalistas e psiquiatras, entre outros. Em muitos deles, a questão da violência doméstica, em particular contra as mulheres, pode ser observada. Nesse fértil cenário, discutiremos, em um estudo de caso, a 
representação sobre a violência doméstica a mulheres em uma série realizada pela Globosat News Television (GNT), Sessão de Terapia (GNT, 2012-2014), e uma novela da Globo, Mulheres Apaixonadas (2003).

\section{A representação da mulher vítima de agressão doméstica: novela versus série}

Nosso primeiro objeto de análise é a série ficcional Sessão de Terapia, que acompanha o cotidiano do psicólogo paulista Theo Cecatto, interpretado pelo ator brasileiro Zécarlos Machado. No Brasil, a série estreou em 1 de outubro de 2012 e teve três temporadas (45 episódios na primeira, 35 na segunda e 35 na terceira temporadas), sendo que o último episódio foi ao ar em 19 de setembro de 2014. Foi dirigida por Selton Mello, ator que em 2011 já havia codirigido outro seriado na TV Globo, A Mulher Invisível. Para fins dessa análise, nosso recorte será o personagem Bianca Cadore, da terceira temporada, interpretada por Letícia Sabatella.

Em relação à novela, escolhemos Mulheres Apaixonadas (Globo, 17 de fevereiro de 2003 a 11 de outubro de 2003), de Manoel Carlos, já que ficou inserida no imaginário brasileiro como "a novela sobre violência doméstica", devido à excelente e controversa atuação dos atores Dan Stulbach, que interpretava o personagem Marcos, e Helena Ranaldi, a Raquel, além da repercussão das "raquetadas" sofridas por esta.

Na ficção seriada analisada, Bianca (Letícia Sabatella) é atendida às segundas, 16h, e diz aceitar os maus tratos do marido por ser apaixonada por ele. Ao longo da temporada, o personagem passou por sete "sessões" (episódios $1,6,11,16,21,26$ e 31). Foram roteiros inéditos, uma vez que a série original possui apenas duas temporadas. Na primeira sessão, Bianca abre o diálogo dizendo que está ali porque o "marido acha que tem alguma coisa errada comigo"; e completa: "Para consertar as coisas entre a gente, eu tinha de vir aqui, então eu vim". Ela começa a compartilhar a imagem que tem do marido com o terapeuta: "Eu não dirijo. Tadeu diz que uma mulher dirigindo é um perigo"; e sorri: "No fundo, ele acha que toda vez que eu parar num farol alguém vai me paquerar. Na farmácia, no supermercado, na oficina...". Nesse sentido, a linha narrativa é 
semelhante à da novela Mulheres Apaixonadas, na qual Marcos (Dan Stulbach) "morre de ciúmes" de Raquel (Helena Ranaldi).

Durante a sessão de Bianca, o psicólogo Theo Ceccato (Zécarlos Machado) nota o pulso machucado da paciente, que percebe e se levanta para disfarçar. Por meio das falas, ficamos sabendo no episódio inicial que Bianca era filha de um italiano apaixonado por literatura - a família teria sido morta num caso fatal de invasão de domicílio no bairro nobre do Morumbi, zona Sul da capital -; cresceu lendo Dante e Boccacio; tornou-se professora; casou-se com o marido mecânico, dono de uma oficina; parou de trabalhar com o nascimento do filho único do casal, Enzo, de sete anos. É inserido, portanto, um conflito clássico das narrativas brasileiras: o casamento entre membros de diferentes classes sociais. Uma problemática a ser introduzida aqui é a questão de que se pode inadvertidamente igualar a classe social mais baixa do marido com a violência doméstica, o que na realidade não é factual. Aliás, de acordo com Joyce e Martinez (2017), a representação de Raquel e Marcos foi positiva, já que iluminou certos aspectos da violência doméstica, como a mudança no estigma que atrela a violência doméstica somente às classes menos favorecidas, com nível menor de educação, geralmente negra ou mestiça - preconceito derivado, entre outros, da falta de intenção de se inserir o negro como cidadão na sociedade brasileira após a abolição, em 1888 (FAUSTO, 2013). A representação da violência doméstica contemporânea nas narrativas midiáticas, portanto, sugere que se trata de um problema que transcende raça e classe, sendo de natureza não somente física, mas também psicológica. Outra correlação a ser feita entre a série e a novela é que a violência é apresentada aos personagens e ao público ao mesmo tempo, em pequenas doses (JOYCE; MARTINEZ, 2017, p. 227).

Vale ressaltar que o caso de Bianca e Enzo é inovador em outro aspecto: ao introduzir a noção de nova classe média, que autores como o economista Marcelo Neri (2011), da Fundação Getúlio Vargas, definiram - antes da crise de 2015 - como a parte da população anteriormente classificada como classe de renda $D$ que, na segunda metade da década de 2000 , teria ascendido à classe $C$. 
Com o casamento, Bianca deixou de ir às óperas e ao teatro que tanto apreciava: "Agora a gente só briga, só discute". Ainda no primeiro episódio, ela revela: "Nas discussões, ele fica alterado, quebra tudo, me machuca", para logo corrigir: "Ele não me machuca, ele me fere, me magoa, você entendeu o que eu quis dizer, né?". Ao longo dos episódios, os conflitos vão emergindo, de uma forma densa³ Em uma telenovela, a trama se desenvolve em um ritmo muito mais lento devido à quantidade maior de capítulos, por exemplo, Caminho das Índias, Mulheres Apaixonadas e, mais recentemente, A Regra do Jogo, novelas que lidaram com a violência doméstica em suas narrativas e tiveram 203, 203 e 167 capítulos, respectivamente, contra 45 e, posteriormente, 35 e 35 das três temporadas de Sessão de Terapia.

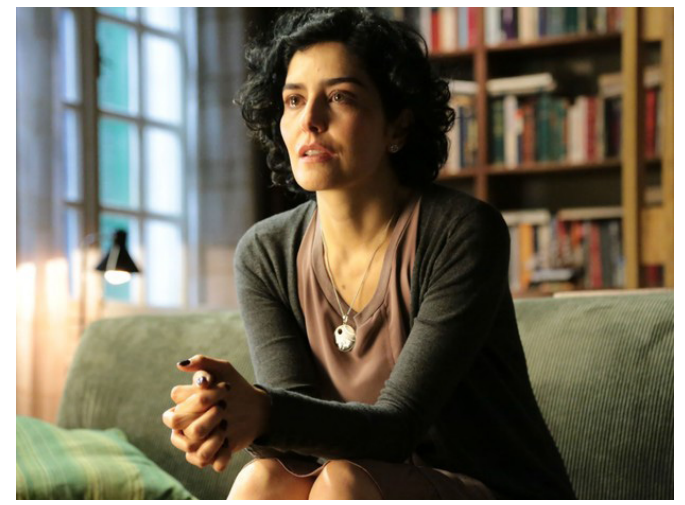

Figura 1: Bianca Cadore, na primeira sessão (Foto: Divulgação/GNT)

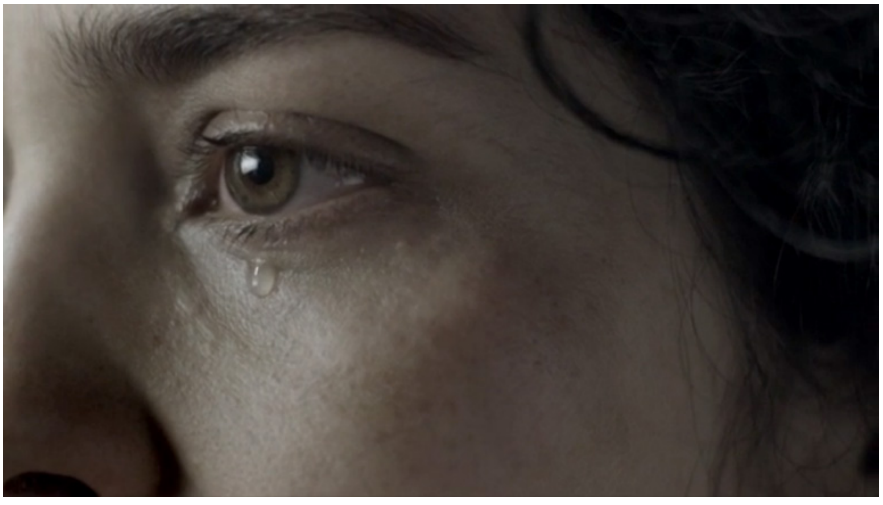

Figura 2: Sessão quatro e as marcas de violência na face (Foto: Divulgação/GNT) 
Em Sessão de Terapia, em sua segunda sessão (episódio 6), Bianca chega com a mão enfaixada, dizendo ter se machucado ao defender o filho de uma briga com seu marido. Na terceira sessão (episódio 11), ao ser pressionada pelo psicólogo, desabafa que não aguenta mais viver sob a desconfiança do marido, revelando novamente que apanha dele, o que leva Theo a aconselhá-la a denunciar o marido à polícia. Na quarta sessão (episódio 16), Bianca chega machucada e conta que o marido tentou matá-la e, para se defender, ela fugiu com o menino, quando Theo novamente a aconselha a ir à polícia. Bianca decide acatar a sugestão, mas pede que ele a acompanhe; o psicólogo, no entanto, diz que ela precisa fazer isso sozinha.

Em Mulheres Apaixonadas, depois de meses sofrendo abuso doméstico e psicológico nas mãos do marido Marcos, Raquel finalmente vai à delegacia das mulheres prestar denúncia. Ao contrário de Bianca, ela não vai sozinha, mas acompanhada da figura que, na narrativa telenovelesca, pode ser comparada à do psicólogo da série: Helena, a heroína de Manoel Carlos, que servia como a "voz da razão", incentivando a amiga Raquel a buscar o total auxílio da lei e levando Raquel à delegacia literalmente pela mão (JOYCE; MARTINEZ, 2017, p. 228).

Na quinta sessão (episódio 21), Bianca revela que foi até a delegacia e o marido foi chamado para depor. "Eu me senti uma traidora... Eu acho que nunca me senti tão angustiada"; e continua: "Eu fiz exame de corpo de delito. Tava morrendo de vergonha, eu tava muito machucada. Eles ficaram fazendo um monte de perguntas e fotografaram meu corpo de tudo quanto é jeito...". No caso de Mulheres Apaixonadas, a representação do passo a passo dentro da delegacia foi feita de maneira mais implícita e didática, talvez pelo seu caráter de merchandising social, buscando incentivar as mulheres a prestar queixa. Por exemplo, de acordo com Joyce e Martinez (2017), quando Raquel vê outras mulheres esperando na sala de espera, ela volta atrás por um breve momento, confessa à amiga Helena que não se sente bem e diz que quer ir para casa. Contudo, Helena convence Raquel a ficar e apresentar queixa, lembrando-a de que todas as outras mulheres estavam no mesmo barco que ela. Daí em diante, as cenas quase não têm diálogo 
e a representação do exame físico é acompanhada de música instrumental. Além disso, na novela, a delegacia é representada como um lugar limpo e seguro, e a oficial da polícia assegura Raquel de que a equipe é qualificada e fará que ela se sinta o mais confortável possível (Ibid., p. 228).

No caso da série, contextualizando o relato de Bianca: a audiência sabe que, naquele momento, ela e o filho estariam escondidos na casa de um amigo do pai dela. Durante a sessão, ela conta que o marido havia tentado matá-la: "Quando ele disse que alguém ia morrer, eu falei que não tinha medo dele... Foi aí que ele colocou as mãos no meu pescoço e começou a apertar...". Após algum tempo, ela diz: "eu sei que ele pode me machucar, que pode machucar meu filho. Mas eu amo esse homem (...). Eu tenho medo de voltar a ser como eu era antes do Tadeu, sozinha. Antes dele a minha vida não era nada. A impressão é que eu comecei a viver depois que eu me casei com o Tadeu". Do ponto de vista mítico grego, portanto, Bianca estaria alinhada com Hera, a consorte de Zeus, ou seja, a imagem do feminino que só existe em função do marido, do masculino (BRANDÃO, 2009; BULFINCH, 1999). Durante a sessão, ela recebe uma ligação que supostamente informa que o marido sabe onde eles estão escondidos e foi atrás do filho - e deixa o consultório correndo. Estaríamos, portanto, diante de um caso de merchandising social, no qual a situação está sendo exposta de forma didática, para ajudar a orientar telespectadores que estão passando pelo mesmo problema. No entanto, estamos no plano da ficção, com seus turning points narrativos ou, no caso da novela, ganchos.

É interessante ressaltar que, tanto no caso de Bianca como no de Raquel, as vítimas não procuram a lei até que a possibilidade da morte seja uma realidade iminente. Outro aspecto que deve ser ressaltado é que, em Mulheres Apaixonadas, as consequências ligadas ao crime de violência doméstica eram completamente diferentes às da atual realidade. Isso sugere que, tanto na representação ficcional quanto na não ficcional, o imaginário ao redor da violência doméstica foi e está sendo transformado. Um exemplo é quando a personagem Raquel suplicava para que Marcos a deixasse em paz e sumisse de sua vida, 
ameaçando entregá-lo para a polícia, e o marido respondia ironicamente que estava "morrendo de medo". Isso se devia ao fato de que, durante a época da transmissão de Mulheres Apaixonadas, a Lei Maria da Penha (Lei 11.340/2006) era inexistente.

De toda forma, a noção de vitimização perante a violência doméstica por meio da personagem Bianca sugere ainda uma tensão nessa representação. $\mathrm{Na}$ sexta sessão (episódio 26) ${ }^{4}$, Theo inesperadamente recebe a visita do marido de Bianca. Tadeu revela, então, que Bianca está em tratamento psiquiátrico desde os 13 anos, pois sofre de surtos psicóticos. Para tirar a dúvida de Theo, Tadeu passa o telefone dele, dos pais dela - que ainda estão vivos, diferentemente da morte trágica que teriam tido - e do psiquiatra que a atende. Quando Tadeu sai, Theo liga para o profissional e confirma que a história de Tadeu é verdade: ela sofre de transtornos mentais. Emerge, portanto, o tema mítico da mulher como tentação, relacionada à serpente, ao corpo, ao pecado (CAMPBELL, 1997, p. 121-125) em religiões monoteístas, como o cristianismo, o islamismo e o judaísmo. E também no plano mitológico, ligada não ao logos de um Apolo, mas ao eros de Dionísio (CAMPBELL, 2015), no qual a linha entre criatividade e loucura é tênue.

"Ela mente o tempo todo", diz Tadeu. Ela era bem-educada e culta, mas Tadeu é um gerente de banco, não um mecânico, a família dela está viva, não há arma alguma em casa. "Você sabe que tem gente que se machuca de propósito... Ela se bate, se machuca". Bianca mentiu para Theo - e para mais dez psicólogos. Na última sessão da temporada (episódio 31), Bianca chega angustiada, dizendo querer encontrar o marido. Theo pergunta pelo paradeiro do filho do casal. Ao saber do local, finge ir ao banheiro para ligar para passar a informação a alguém. Bianca tenta fugir, porém Theo a impede de escapar. Ao final, o marido chega para interná-la. Do ponto de vista da representação midiática, portanto, a série aponta o feminino como o grande símbolo da vida, 
bela em seus papéis de mulher e mãe, mas se trata de um feminino ferido, exibido em sua contraparte sombria, serpentina, que mente e manipula, chegando ao extremo de tentar se autodestruir.

Alcântara e Calazans entendem como publicização dos espaços privados e mercantilização dos afetos íntimos a exposição televisiva dos dramas íntimos, medos e inseguranças dos pacientes, ainda que ficcional, ao revelarem seus medos e inseguranças a cada sessão, suscitando um "olhar voyer do telespectador [que] assiste àquilo que outrora deveria ser guardado no âmbito privado de uma consulta" (2015, p. 202). É certamente uma forma de ver a questão, mas talvez um outro olhar também seria o pedagógico, no sentido de familiarizar os telespectadores com a possibilidade de compartilhamento de conteúdos privados em espaços dedicados a isso, como as sessões de terapia.

No sentido do "olhar pedagógico", lembramos que as telenovelas brasileiras, principalmente as da Globo, utilizam a ferramenta do merchandising social, a qual trabalha em via dupla. Além do caráter pedagógico-educativo, ela ajuda a sacramentar a preocupação com o caráter "social" da emissora no imaginário do público. Como Schiavo (2006, p. 2) sugere, dentro da Globo existe uma cultura geral de adoção de uma abordagem social crítica em todos os níveis de programação, com uma clara intencionalidade educacional para as representações. É importante ressaltar também que, no caso das novelas, o merchandising social funciona não somente dessas maneiras previamente descritas, mas como uma poderosa ferramenta usada, ainda que indiretamente, para angariar verbas, dinheiro e audiência, principalmente na TV aberta.

Como já definimos, o merchandising social decorre do merchandising comercial, ou seja, estratégias comerciais são utilizadas para "vender mensagens pró-sociais" ao mesmo tempo em que promovem bens de consumo: um batom, uma marca, a própria telenovela ou a ideologia de uma emissora socialmente responsável, que se destina a lucrar com sua produção. Assim como Fernandes e Santos (2008) ressaltaram, não se pode saber o exato interesse da Globo em divulgar mensagens pró-sociais via merchandising social, afinal, esse tipo de 
marketing não traz lucro de forma direta. Mas os autores concordam que pode ser uma maneira de conquistar um público cativo devido à suposta responsabilidade social da emissora (Ibid., p. 8). Como sabemos, o número da audiência (determinado pelo Instituto Brasileiro de Opinião Pública e Estatística - Ibope) está diretamente relacionado ao preço da inserção comercial, seja pelo tradicional comercial, seja pelo merchandising inserido à narrativa da novela.

\section{Considerações finais}

Este estudo fez uma análise comparativa entre duas produções seriadas televisivas: a série Sessão de Terapia (GNT, 2012-2014) e a telenovela Mulheres Apaixonadas (Globo, 2003). O recorte é a representação sobre a violência doméstica a mulheres. No caso da telenovela, a extensão maior (203 capítulos versus 35 da série) permite o aprofundamento maior da temática. Ainda assim, não há em nenhum dos dois casos uma exposição maciça do fenômeno, sendo a violência apresentada aos personagens e ao público ao mesmo tempo e em doses homeopáticas (JOYCE; MARTINEZ, 2017, p. 227).

Destacam-se outros dois diferenciais. O primeiro é que a série é "fechada", isto é, é gravada a partir de um roteiro previamente definido, não dependendo tanto da aprovação do público. Com isso, o personagem pode ser bem mais complexo, tanto que o personagem de Bianca pode ter um turning point narrativo interessante, ao ser revelado que é portador de um transtorno psicológico. Outro grande diferencial parecer ser a questão do merchandising social, neste estudo de caso encontrado somente na telenovela. Isso faz que essas produções narrativas, ao associarem tanto a duração maior quanto a característica prósocial, tenham um desenvolvimento de cenas mais didático quanto à questão. Ainda assim, é relevante ressaltar que as telenovelas, ainda que idealizadas com motivos pró-sociais, são produtos comerciais. Assim, a totalidade das motivações que movem autores(as) e suas equipes, bem como as emissoras, estão diretamente ligadas às mensurações de audiência e, consequentemente, ao faturamento da produção. 
Também deve-se ressaltar que, tanto na série quanto na telenovela analisadas, as vítimas não procuraram a lei até que a possibilidade da morte fosse uma realidade. Isso pode sugerir que, tanto na representação ficcional quanto na não ficcional - e ainda que pese o fato de que o imaginário ao redor da violência doméstica esteja felizmente em transformação - , o aspecto relacional ainda é mais forte do que o lógico na esfera da psiquê feminina. Entre a guerra e o amor, a mulher dá prioridade aos afetos - salvo se estiver em risco de vida.

\section{Referências}

ALBERTI, V. Manual de História Oral. 3. ed. Rio de Janeiro: FGV, 2005.

ALCANTARA, P. C. M.; CALAZANS, F. Crise dos afetos: intimidade e cotidiano no cinema e na televisão. Revista Galáxia, São Paulo, n. 29, p. 195-206, 2015.

BAITELLO JÚNIOR, N. O animal que parou os relógios. São Paulo: Annablume, 1997.

A era da iconofagia: reflexões sobre imagem, comunicação, mídia e cultura. São Paulo: Paulus, 2014.

BALOGH, A. M. O discurso ficcional na TV: sedução e sonho em doses homeopáticas. São Paulo: Edusp, 2002.

BARROS, A. T. M. P. Imagens do passado e do futuro: o papel da fotografia entre memória e projeção. Revista Matrizes, São Paulo, v. 11, n. 1, p. 149-164, 2017. 
BELTING, H. Antropología de la imagen. Madri: Katz, 2007.

BERTAUX, D. Narrativas de vida: a pesquisa e seus métodos. Natal: Editora da UFRN; São Paulo: Paulus, 2010.

BRANDÃO, J. DE S. Mitologia grega. Petrópolis: Vozes, 2009. 3 v.

BULFINCH, T. O livro de ouro da mitologia: história de deuses e heróis. 8. ed. Rio de Janeiro: Ediouro, 1999.

CAMPBELL, J. O herói de mil faces. 10. ed. São Paulo: Cultrix/Pensamento, 1997. . Deusas: os mistérios do divino feminino. São Paulo: Palas Athena, 2015.

CANCLINI, N. G. Culturas híbridas: estratégias para entrar e sair da modernidade. 3. ed. São Paulo: Edusp, 2000.

CASSIRER, E. Ensaio sobre o homem. São Paulo: Martins Fontes, 1994.

CASTELLS, M. A sociedade em rede: a era da economia, sociedade e cultura. São Paulo: Paz e Terra, 2005.

CASTRO, E. V. DE. Metafísicas canibais: elementos para uma antropologia pósestrutural. São Paulo: Cosac Naif, 2015.

CONTRERA, M. S. Mediosfera: meios, imaginário e desencantamento do mundo. São Paulo: Annablume, 2010. 
DE MASI, D. Descoberta e invenção: criatividade e grupos criativos. Rio de Janeiro: Sextante, 2005.

DEBORD, G. A sociedade do espetáculo: comentários sobre a sociedade do espetáculo. Rio de Janeiro: Contraponto, 1997.

DRAVET, F. Crítica da razão metafórica: magia, mito e poesia na cultura contemporânea. 1. ed. Brasília: Casa das Musas, 2014.

FAUSTO, B. História do Brasil. 14. ed. São Paulo: Editora da USP, 2013.

FERNANDES, M. V.; SANTOS, S. dos. Merchandising: a sua relevância nas telenovelas brasileiras, com ênfase na rede. In: CONGRESSO DE CIÊNCIAS DA COMUNICAÇÃO NA REGIÃO NORTE, 7., 2008, Boa Vista. Anais... Boa Vista: Intercom - Sociedade Brasileira de Estudos Interdisciplinares da Comunicação, 2008. Disponível em: <https://goo.gl/Yv7o9S>. Acesso em: 17 out. 2017.

FLUSSER, V. Da religiosidade: a literatura e o senso de realidade. São Paulo: Escrituras, 2002.

GOMES, M. R. ; SOARES, R. Por uma crítica do visível. 1. ed. São Paulo: Midiato, 2015.

HAMBURGER, E. O Brasil antenado: a sociedade da novela. Rio de Janeiro: Jorge Zahar, 2005.

JENKINS, H. Cultura da convergência. 2. ed. São Paulo: Aleph, 2009.

JOYCE, S. N. Brazilian telenovelas and the myth of racial democracy. Maryland: Lexington Books, 2012. 
JOYCE, S. N.; MARTINEZ, M. Os BRICS e as narrativas midiáticas: a proximidade entre as notícias e as telenovelas brasileiras. Brazilian Journalism Research, Brasília, DF, v. 12, n. 1, p. 82-101, 2016.

- From social merchandising to social spectacle: portrayals of domestic violence in TV Globo's prime-time telenovelas. International Journal of Communication, Los Angeles, v. 11, n. 1, p. 220-236, 2017.

JUNG, C. G. A natureza da psique - a dinâmica do inconsciente. 9. ed. Petrópolis: Vozes, 2012. Coleção Obra Completa, v. 8/2.

KÜNSCH, D. A. A comunicação, a explicação e a compreensão: ensaio de uma epistemologia compreensiva da comunicação. Líbero, São Paulo, v. 17, n. 34, p. $111-122,2014$.

LA PASTINA, A. Selling political integrity: telenovelas, intertextuality, and local elections in rural Brazil. Journal of Broadcasting and Electronic Media, Abingdon, v. 48 , p. $302-325,2004$.

LA PASTINA, A.; PATHEL, D. S.; SCHIAVO, M. Social Merchandizing in Brazilian Telenovelas. In: SINGHAL, A. et al. (Eds.). Entertainment-education and social change: history, research and practice. New York: Routledge, 2003. p. 261-277.

LINS, C. O documentário de Eduardo Coutinho: televisão, cinema e vídeo. Rio de Janeiro: Jorge Zahar, 2004.

MARTÍN-BARBERO, J. Dos meios às mediações: comunicação, cultura e hegemonia. 2. ed. Rio de Janeiro: Editora da UFRJ, 2003. 
MARTÍN-BARBERO, J.; REY, G. Os exercícios do ver: hegemonia audiovisual e ficção televisiva. São Paulo: Senac São Paulo, 2001.

MARTINEZ, M. A vida em 20 linhas: a representação da morte nas páginas da Folha de S.Paulo. Intercom - Revista Brasileira de Ciências da Comunicação, São Paulo, v. 37, n. 2, p. 71-90, 2014.

A história de vida como instância metódico-técnica no campo da Comunicação. Comunicação \& Inovação, São Caetano do Sul, v. 16, n. 30, p. 75-90, jan./abr. 2015.

. Reflexões sobre Jornalismo e História Oral: um campo com mais convergências do que dissonâncias. Revista Observatório, Palmas, v. 2, n. 1, p. 75-91, 2016.

MARTINEZ, M.; CORREIA, E. L. ; PASSOS, M. Y. R. Entre fato e ficção: personagens compostos versus fraude em jornalismo. Estudos em Jornalismo e Mídia, Santa Catarina, v. 12, n. 2, p. 238-250, 2015.

MARTINEZ, M.; SILVA, M. C. C. Entrevista com o professor doutor Jorge A. Gonzalez. Tríade, Sorocaba, v. 5, n. 9, p. 246-253, 2017.

MASIP, P. et al. Active audiences and journalism: involved citizens or motivated consumers? Brazilian Journalism Research, Brasília, DF, v. 1, n. 1, p. 234-255, 2015.

MEDINA, C. Narrativas da contemporaneidade: epistemologia do diálogo social. Tríade, Sorocaba, v. 2, n. 4, p. 8-22, 2014.

MEIHY, J. C. S. B. Manual de história oral. 2. ed. São Paulo: Loyola, 1998. 
MORIN, E. O Homem e a morte. Rio de Janeiro: Imago, 1997.

MOTTA, L. G. Análise crítica da narrativa. Brasília, DF: Editora UnB, 2013.

NERI, M. C. (Coord.). A nova classe média: o lado brilhante dos pobres. Rio de Janeiro: FGV/CPS, 2011.

PORTO, M. Media power and democratization in Brazil: TV Globo and the dilemmas of political accountability. New York: Routledge, 2012.

RAMOS, D. G. Entregêneros: representações do feminino na teledramaturgia brasileira. Tese (Doutorado em Meios e Processos Audiovisuais) - Escola de Comunicações e Artes, Universidade de São Paulo, São Paulo, 2016.

SCHIAVO, M. R. Dez anos de merchandising social. In: CONGRESSO BRASILEIRO DE CIÊNCIAS DA COMUNICAÇÃO, 29., 2006, Brasília. Anais... Brasília, DF: Intercom - Sociedade Brasileira de Estudos Interdisciplinares da Comunicação, 2006. Disponível em: <https://goo.gl/45BeLN>. Acesso em: 17 out. 2017.

SILVA, M. C. C. Comunicação e cultura antropofágicas: mídia, corpo e paisagem na erótico-poética oswaldiana. 1. ed. Porto Alegre: Sulina; Sorocaba: Editora da Uniso, 2007.

SOARES, R. L. ; VICENTE, E. Entre o rádio e a televisão: gênese e transformações das novelas brasileirase. E-Compós, [S.I.], v. 19, n. 2, p. 1-17, 2016.

SODRÉ, M. A narração do fato: notas para uma teoria do acontecimento. Petrópolis: Vozes, 2009. 